INVESTIGACIÓN

Recibido: 18/05/2020 --- Aceptado: 14/12/2020 --- Publicado: 12/03/2021

\title{
ICONOGRAFÍAS EN PRENSA DIGITAL SOBRE LA PANDEMIA DE COVID-19: UN RETRATO CULTURAL DEL CORONAVIRUS EN ESPAÑA EN ABRIL DE 2020
}

\section{Iconographies in digital newspapers on the COVID-19 pandemic: a cultural portrait of the coronavirus in Spain in april 2020}

Angélica García-Manso: Universidad de Extremadura. España angelicamanso@hotmail.com

\section{RESUMEN}

La pandemia que ha afectado en el año 2020 a un mundo globalizado como el contemporáneo posee una vertiente comunicativa que es, fundamentalmente, gráfica, de representación o ilustración, la cual es objeto de análisis a partir de las cabeceras digitales de periódicos españoles. En estos, se muestra la importancia de los vínculos tipo "app", del recurso al "isotipo" y de una concepción visual que se adapta a la iconografía clásica de la gorgona Medusa. Tales caracterizaciones aportan claves no sólo estéticas, sino sociopolíticas y de su exposición o comunicación pública, en dos direcciones: la amenaza y la protección.

PALABRAS CLAVE: Periodismo - Iconografía - Logotipos digitales - Isotipos Tradición Mitológica.

\section{ABSTRACT}

The pandemic that has affected a globalized world like the contemporary one in 2020 has a communicative aspect that is, fundamentally, graphic, of representation or illustration, which is the object of analysis from the digital headlines of Spanish newspapers. In these, the importance of the "app" type links, the use of the "isotype" and a visual concept that adapts to the classic iconography of the Medusa gorgon are shown. Such characterisations provide keys not only to aesthetics, but also to sociopolitics and to their exposure or public communication, in two directions: threat and protection.

\footnotetext{
1 Angélica García Manso es profesora universitaria y de ESO y Bachillerato; es Doctora en Historia del Arte con una tesis sobre la interrelación entre literatura e imagen, sea iconográfica, mitológica o figurativa, en la pintura y el cine. Pertenece al Grupo de Investigación MUSAEXI, de la UEx.
} 
KEY WORDS: Journalism - Iconography - Digital logos - Isotypes - Mythological tradition.

\section{ICONOGRAFIAS NA MÍDIA DIGITAL SOBRE A PANDEMIA DE COVID-19: UM RETRATO CULTURAL DO CORONAVÍRUS NA ESPANHA EM ABRIL DE 2020}

\section{RESUMO}

A pandemia que tem afetado o ano de 2020 ao mundo globalizado como o contemporâneo possui uma vertente comunicativa que é, fundamentalmente, gráfica,de representação ou ilustração, a qual é objeto de análise das manchetes das mídias digitais de jornais da Espanha. Nestes, se mostra a importância dos vínculos tipo "app", do recurso ao "isotipo" e de uma concepção visual que se adapta a iconografia clássica da górgona Medusa. Tais caracterizações aportam fatos não somente estéticos, mas também sociopolíticos e da sua exposição ou comunicação pública, em duas direções: a ameaça e a proteção.

\section{PALAVRAS CHAVE}

Jornalismo; Iconografía; Logotipos digitais; Isotipos; Tradição Mitológica

Cómo citar el artículo:

García-Manso, A. (2021). Iconografías en prensa digital sobre la pandemia de COVID-19: un retrato cultural del coronavirus en España en abril de 2020. Vivat Academia. Revista de Comunicación, 154, 45-61. http://doi.org/10.15178/va.2021.154.e1234 http://www.vivatacademia.net/index.php/vivat/article/view/1234

\section{INTRODUCCIÓN: GLOBALIZACIÓN Y PANDEMIA}

Además de sus implicaciones sanitarias, la pandemia provocada por el coronavirus SARS-CoV-2, causante de la enfermedad conocida con el nombre de COVID-19 (a partir del acrónimo en inglés acompañado del guarismo del año de detección de su morbilidad en seres humanos), también ha puesto de manifiesto la constatación de cómo existe un sistema planetario de interacciones que, como resultado de la cultura globalizada, comparte no sólo el contagio del virus, sino también la representación de la epidemia que este provoca y, por descontado, sus formas de comunicación.

Se trata de una representación que es simultáneamente alfabética e icónica. Así, en lo que se refiere a la deixis léxica, el término "coronavirus" goza de acierto lingüístico a partir de su aceptación en las lenguas occidentales, pues como cultismo tiene sus orígenes en la lengua latina en las dos partes de la palabra, tanto en los términos por separado ("corona" y "virus") como en su formación compuesta. El inglés como lengua vehicular globalizada ha adaptado perfectamente su pronunciación 
(/kə'rəunə,varrəs/, en transcripción fonética, con un sonido vocálico débil que, incluso en la lengua inglesa, permite una pronunciación versátil perfectamente comprensible en cualquier nivel lingüístico), a la vez que como neologismo se ha impuesto en las restantes lenguas, de origen indoeuropeo o no, con alfabetos de toda índole: como koronaawirus en polaco о коронавирус en ruso, por poner dos ejemplos.

En un orden de cosas diferente, la idea de "virus" se generalizó con un uso cultista y científico con el desarrollo de la medicina moderna, con lo cual aleja el concepto más habitual de "peste", que adquiere connotaciones semánticas de otra índole, distintas de las intrínsecamente relativas a la salud. Por otra parte, el descubrimiento biológico de la singularidad del virus SARS-Cov-2 con moléculas dispuestas en puntas aportó la idea, también noble de "corona". En fin, el origen de la epidemia en animales exóticos y, en general, en murciélagos provoca la asociación inmediata con un mito moderno relacionado con enfermedades pestíferas, el mito literario de Drácula, que confiere el origen de su protagonista en unos atávicos territorios eslavos enfáticamente orientales -aunque sean del este de Europa y no de China, origen de la actual pandemia-, y, además, enlaza la figura del vampiro con la idea de transformación en quirópteros.

En definitiva, el rastreo de la palabra encarna en sí misma una historia cultural tanto la del mundo globalizado como la de Occidente propiamente dicho. De ahí que se haga hincapié más en la influencia de la ominosa figura nacida de la pluma de Bram Stoker, según hemos señalado, que en las surgidas de tradiciones no europeas relacionadas con contagios letales. En efecto, entre los símbolos globalizados de la peste se encuentra el murciélago a pesar de su benéfico papel en el control de plagas de insectos, pero también y sobre todo la asociación nefasta se da con ratas, animal que en la actualidad más bien se puede relacionar con los experimentos de laboratorio, sin que, en el marco de las investigaciones biológicas y de control de enfermedades como la viruela, exista ya una nítida conexión entre los mamíferos con la causa (se trata de vectores de transmisión) y se descubra la necesidad de dar visibilidad a un ente invisible como una molécula.

Todo lo expuesto, aunque de manera sintética, permite constatar cómo existen referentes léxicos y culturales que, en torno a la pandemia planetaria del año 2020, derivan en tratamientos icónicos susceptibles de un análisis singular. No obstante, es necesario comprender cómo la iconografía contemporánea procede a partir de dos premisas: en primer lugar, el diseño como clave de información y mercadotecnia, de forma que se identifican productos, marcas o empresas mediante logotipos en sus diversos desarrollos (también objetos y conceptos); en segundo lugar, la interfaz informática potenciada desde finales de los años 60 (fundamentalmente en los laboratorios de Xerox Parc) que estableció la metáfora del escritorio y la identificación de procesos mediante figuras identificadoras. Con la generalización de uso de los smartphones prácticamente a las puertas del siglo XXI, tales procedimientos se funden con la aparición de las denominadas "app", las cuales, frente a la diversidad de plataformas se convierten en atajos eficaces del alfabetismo implícito

Vivat Academia. Revista de Comunicación. 2021, n 154, 45-61 
en las webs. En este contexto, aplicado a las circunstancias de la enfermedad COVID19 y del coronavirus causante, surgen unas respuestas iconográficas concretas.

En efecto, sin voluntad de ser exhaustivos, es nuestro propósito proceder al análisis de la iconografía asociada al coronavirus que provoca la enfermedad de COVID-19 en algunos testimonios de proximidad. El vehículo más extendido a este respecto es el de la aparición del icono en las pantallas, sea mediante vínculos webs y enlaces a "apps", sea en medios de comunicación, redes sociales o programas específicos, en los que es posible percibir elementos concomitantes, y, sobre todo, unos rasgos compartidos y otros particulares, portadores de unas realidades coyunturales más o menos explícitas, más o menos subliminales. Todo ello se ha de calibrar con la consciencia de que la iconografía significa la reducción de un ente complejo a un elemento conceptual, es decir, que se reconoce el todo por la parte, el conjunto por el esquema.

La metodología de referencia resulta inevitablemente ecléctica. De un lado, se cuentan los estudios de iconografía efectuados desde la perspectiva de la Historia del Arte que hunden sus raíces en las aportaciones que acerca de la alusión icónica estableció Erwin Panofsky (1955 y 2008), con referencias además a los análisis más concretos llevados a cabo por Ernst Gombrich (2003) o Jean Seznec (1983); se trata de una base que permite describir el logotipo. De otro lado, importan las claves generadas desde los estudios de semántica de la escuela de Charles Sanders Peirce llevados a cabo a caballo entre los siglox XIX y XX sobre la noción de símbolo y la de Roland Barthes (1971 y 1991) acerca del carácter supralingüístico y cultural de dicho símbolo, claves en las que se apoya la interpretación del logotipo. Finalmente, la funcionalidad de los logotipos se considera a partir de la síntesis que, al respecto de la figuración en los medios periodísticos, se descubre en las reflexiones efectuadas por el ensayista Gonzalo Peltzer (1991); ello sin olvidar los aspectos técnicos de la comunicación digital y sus interfaces.

\section{OBJETIVO: RECONOCIMIENTO DE FORMAS $Y$ MOTIVOS DE LA ICONOGRAFÍA DIGITAL ACERCA DEL CORONAVIRUS/COVID-19}

Interactividad y usabilidad constituyen dos de los aspectos básicos que, de acuerdo con las directrices de interfaz humana (HIG de cada sistema operativo), se requieren de una herramienta que sea versátil y esté integrada en los medios tecnológicos contemporáneos de comunicación en red; se trata de las conocidas "apps". A este respecto, el proceso de iconización de las "apps" relativas a coronavirus/COVID-19 posee, en principio, el inconveniente de su novedad, que impide la rápida identificación de enseres usuales o de uso ya generalizado (una estantería para marcar carpeta de archivos, por ejemplo; o la letra $W$ como referente de un programa o "app" de tratamiento de textos a partir de la marca de uso más estandarizado). El uso es, sobre todo, de acceso, de enlace o vínculo a información o a cuestionarios concretos acerca de la pandemia. 
¿Cómo lograr una rápida identificación, objetivo primordial de la información gráfica (Costa, 1998)? A pesar de la adaptación del idioma y su carácter prácticamente universal, la longitud de la palabra compuesta impide su eficacia a este respecto. Derivado de ello se impone una caracterización prevalentemente figurativa, aunque, según veremos, con tal número de aspectos asociados que, inevitablemente, se requerirá su especificación mediante expresiones en cada lengua concreta. Ahora bien, el motivo prevalente será, a primer golpe de vista, la ilustración, es decir, lo propiamente gráfico, si bien se hacen necesarias otras precisiones. Así, sin entrar en detalles sobre la tradición semiótica y sus bases metodológicas, se entiende por ideograma un símbolo en una cadena de comunicación (es decir, no se trata de un símbolo único, sino, por poner el ejemplo de las señales de tráfico, un motivo gráfico que tiene sentido en el conjunto de indicadores visuales para la circulación de vehículos). Ciertamente, el campo del coronavirus/COVID-19, a pesar de tratarse de un motivo de carácter biológico, no establece interconexiones con otros símbolos, excepción hecha del símbolo genérico de "biohazard"2. De esta manera, únicamente la consideración de forjar unos logotipos autónomos prevalece a la hora de afrontar su composición visual.

Pero el concepto de logotipo propiamente dicho posee, incluso por definición etimológica, un carácter tipográfico, donde la información alfabética complementa la figuración o, donde, a la inversa, es la ilustración la que confiere sentido a las letras. En el extremo opuesto se encuentra la forma denominada "isólogo", una imagen que integra las letras en el diseño, como una especie de caligrama. Entre ambos, el "imagotipo" supone la suma de figura y texto, pero dispuestos en planos diferentes. Trasladada esta tipología al entorno de las "apps", resulta explicable que, dado el tamaño de los botones de una "app" en una pantalla, resulte más difícil el desarrollo de "imagotipos", de forma que prevalezca los modelos del "isólogo" y del "isotipo". En el caso específico del coronavirus y de la enfermedad derivada el "isotipo" constituirá el componente visual más importante (según sucede también en el diseño arquitectónico; véase Carazo \& Galván, 2017), salvo que se recurra a la composición de una palabra solamente con consonantes, como "CNVRS" o la propia palabra "COVID" (que de por sí es el acrónimo en inglés de "enfermedad de coronavirus", como corona-virus disease).

Según se expondrá, probablemente el diseño más esquemático de los "isotipos" creados en torno a coronavirus/COVID-19 corresponde al denominado en arte rupestre como soliforme; se trata de un sol radial, con cortas varillas, de conformidad con la imagen de laboratorio más extendida de la molécula y que, además, le da nombre: es decir, una corona de forma solar por sus extensiones radiales o rayos.

\footnotetext{
2 Se trata de un símbolo con clave Unicode propia que fue ideado en el año 1966 gracias a un ingeniero de una empresa multinacional de productos químicos con el fin de alertar de la peligrosidad asociada a la manipulación biológica; el símbolo fue divulgado a partir del año siguiente por la revista Science (Baldwin \& Runkle, 1997). Versiones retocadas de este símbolo se suelen utilizar en alusión genérica a virus.
} 
García-Manso, A.

Iconografias en prensa digital sobre la pandemia de COVID-19: un retrato cultural del coronavirus en España en abril de 2020

El grafismo también resulta parecido con el símbolo habitual del enlace a los "ajustes" en los sistemas operativos, como una rueda dentada, imagen que procede de los engranajes mecánicos de relojería (de ahí la idea de ajuste que solía iniciarse con los datos de hora y fecha). Por ejemplo, en lo que se refiere a las "apps" 3 , tales modelos se descubren en el icono del botón que se ha elaborado desde el Servei Català de la Salut, icono que se presenta como un isólogo compuesto de un isotipo y dos textos complementarios en niveles diferentes y abreviados, uno institucional recreado a partir de la barra de jerarquización de una dirección informática referida al responsable el enlace, y otro con un tono más cómplice que se ofrece como vínculo web bajo el lema "stop COVID19 cat". Pues bien, se trata de un logotipo elaborado, que parte de una idea de desplazamiento de la corona: un círculo blanco sobre el que se superpone levemente descentrado la rueda descrita, superponiéndose el motivo soliforme (si bien sin rayos, que se dejan para el siguiente motivo) con el relativo a la rueda dentada, a la que se dota de un tono rojizo y aparece expuesta como un eclipse. La suma de sendos motivos superpuestos enriquece la información polisémica que se propone: el tema del coronavirus y su eclipse o vuelta al resplandor tras haber sido superpuesto.

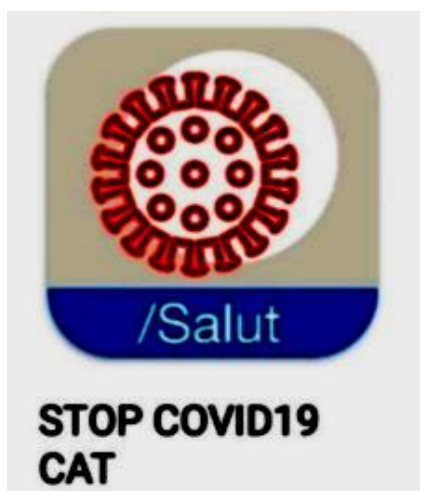

Ilustración 1: Enlace de "app" Stop Covid19 Cat

Fuente: Servei Català de la Salut.

Los rayos en la rueda descrita tienen forma levemente trapezoidal, siendo más anchos hacia fuera que hacia la corona interior, con un aspecto final como tachones, según una forma que aparece en otras propuestas de logotipos coronavirus/COVID19. El color rojo suele ser predominante, sea como positivo (con la figura en rojo) o como negativo (figura sobre fondo rojo), con diferentes opciones de tonalidad, atenuación, contraste, etcétera. La prevalencia del rojo se asocia a la fisicidad orgánica de la sangre y, por asociación evidente, a la medicina. Pero los matices se presentan en las variaciones del esquema elemental que acabamos de describir. También el color azul suele aparecer, sea como dominante en el conjunto del logotipo, o como parte de este (como sucede en la "app" del Servei Català de la

\footnotetext{
${ }^{3}$ En el momento en que se escriben estas líneas no existe un repertorio cerrado de "apps", dado que la actualidad de la pandemia impone iniciativas en continua transformación. Así, los dos casos que se aducen lo son como ejemplo de la relación que se da entre los iconos de las apps y los enlaces de los periódicos, sin afán de recopilación.
} 
García-Manso, A.

Iconografias en prensa digital sobre la pandemia de COVID-19: un retrato cultural del coronavirus en España en abril de 2020

Salut). En definitiva, los vectores clave o de reconocimiento inmediato son el soliforme/rueda dentada y los colores rojo y, secundaria o subsidiariamente, azul.

Otra "app" española que busca adaptar el modelo de control de la enfermedad en Corea del Sur conocida como "Proyecto Open Coronavirus", en desarrollo en el momento actual y con código en abierto, mantiene, de manera elocuente aunque de forma aún más esquematizada si cabe que la del Servei Català de la Salut, las ideas del eclipse y del deslizamiento, pero aporta sobre todo un predominante e impactante color rojizo, como un negativo fotográfico.

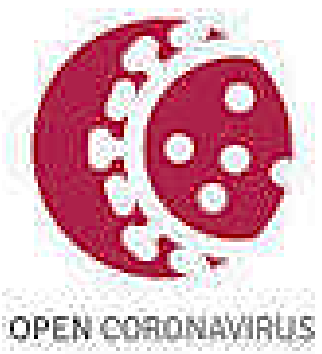

Ilustración 2: Enlace de "app" Open Coronavirus

Fuente: https://github.com/open-coronavirus/open-coronavirus .

De igual forma se comprueba también si se traslada el modelo de enlace de "app" a los vínculos gráficos en las páginas web de la prensa digital ${ }^{4}$, tal como se muestra, por ejemplo, mediante el icono soliforme al que recurren como "isotipo" las diferentes cabeceras de El Periódico ${ }^{5}$, como, entre otras, El Periódico Extremadura. En este el diferente grosor de las borlas que cierran los rayos y la diferente longitud de tales radios impiden su confusión con el astro y dibujan un negativo del coronavirus en blanco sobre rojo intenso:

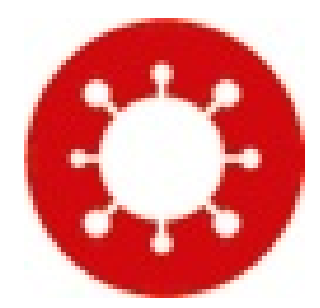

Ilustración 3: Vínculo de portada digital del diario El Periódico Extremadura.

Fuente: El Periódico Extremadura, abril de 2020.

\footnotetext{
${ }^{4}$ En verdad, si bien al margen de lo relativo específicamente a la técnica de los hipervínculos, la importancia de la gráfica informativa en la prensa escrita guarda en el último medio siglo una íntima relación con la extensión de la infografía (De Pablos, 1999; Gamonal, 2013), sobre todo con la de carácter interactivo (Cairo, 2008). Sea como fuere, la historia de la información visual propugna de fondo la creación de una iconografía visual específica (Peltzer, 1991).

${ }^{5}$ Grupo Zeta (perteneciente en la actualidad a Prensa Ibérica S.A.).
} 
Ahora bien, el icono de El Periódico no constituye un "isotipo" puro, por cuanto, al no ser una "app", la imagen acompaña a otra serie de iconos que enlazan diferentes aspectos del tratamiento informativo sobre la pandemia. En el presente soliforme se acompaña a las expresiones "Las claves. Todo lo que hay que saber". Se trata de una expresión cuyo enunciado declara taxativamente que el motivo icónico dominante en el conjunto es el del soliforme que se acaba de describir, que este constituye la suma de las citadas "claves".

En el próximo epígrafe procederemos a describir la caracterización que se ha hecho en la prensa digital española durante el mes de abril de 2020 de los "isotipos" referidos a coronavirus/COVID-19. A este respecto, la plataforma kiosko.net se recoge el mayor corpus de enlaces a las cabeceras periodísticas con versión o difusión digital. Su distribución básica responde a una agrupación geográfica y temática. A este respecto, no resulta difícil acceder a la prensa de "información general" (de ámbito local, regional o nacional) que se edita en España. La selección de cabeceras para el estudio ha partido de dos premisas: se recogen aquellos periódicos que recurrían a enlaces icónicos mediante botones, y la singularidad de tales iconos en función del grupo editorial al que pertenecían los periódicos (de forma que basta con seleccionar un único diario del grupo, pues, de manera indiferente, todos los periódicos editados suelen repetir los motivos; de hecho, se ha elegido el que ofrecía algún tipo variación a este respecto, como es el caso del Comercio de Asturias).

\section{METODOLOGÍA: EXAMEN DE LOS "ISOTIPOS" EN LAS VERSIONES DIGITALES DE LA PRENSA EN ESPAÑA}

En la paulatina adaptación al doble formato impreso/virtual de las distintas cabeceras de los periódicos en España resulta cada vez más relevante el recurso a enlaces y vínculos digitales específicos, los cuales, en el caso de noticias o temas de índole extraordinaria (caso de la pandemia de coronavirus), se presentan en un lugar relevante a la vez que sinóptica (Otero, López \& González, 2012; Orero y Cebrián, 2019). El recurso al modelo de botón de "app" se puede comprobar en la mayor parte de los vínculos de las portadas digitales (sin que falten excepciones, por descontado) con propuestas singulares en el marco de las variaciones de un icono que se encuentra en trance de universalización. Entre los iconos más relevantes destacan por las claves de lectura que aportan los que se exponen a continuación.

Así, en La Vanguardia 6 se ofrece una corona circular en tonos rosáceos e interior rojo, con línea de tachones de coronavirus en blanco al igual que el globo terráqueo interior, cuyos continentes se delimitan en el mismo color blanco. Se trata de un botón que sitúa su objeto en un ámbito globalizado a la vez que como un soliforme interno, que transforma el planeta en estrella, y un corazón terráqueo de contenido eminentemente geográfico. La pandemia se muestra mediante un escudo redondo

\footnotetext{
${ }^{6}$ Grupo Godó.
} 
García-Manso, A.

Iconografias en prensa digital sobre la pandemia de COVID-19: un retrato cultural del

coronavirus en España en abril de 2020

como las dos caras de los contagios: su universalidad y la necesidad de una protección.

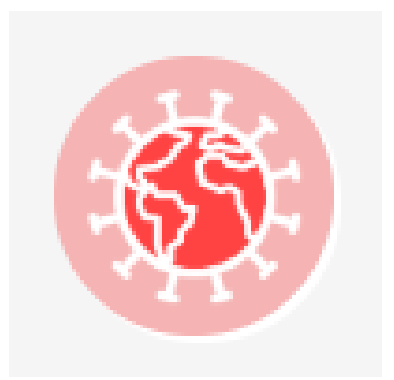

Ilustración 4: Vínculo de portada digital del diario La Vanguardia.

Fuente: La Vanguardia, abril de 2020.

El Diario de Sevilla 7 por su parte presenta una doble corona azul patinada tachonada y dos rupturas minúsculas, aunque visibles, prácticamente en vertical que conducen a un interior en el que se aprecia en negativo de blanco sobre un azul atenuado el muelle de una cadena de ADN/ARN, que aporta al icono una clave bioquímica, que evita el rojo biológico presente en otros logotipos. La rueda está rota, lo cual aporta un fuerte sentido dramático a la amenaza representado por el coronavirus.

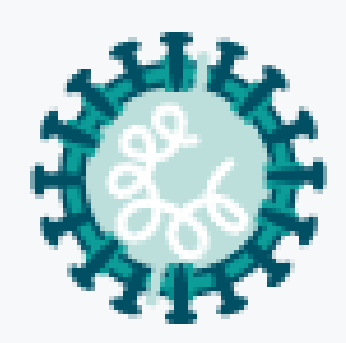

Ilustración 5: Vínculo de portada digital del periódico Diario de Sevilla.

Fuente: Diario de Sevilla, abril de 2020.

El Comercio de Asturias ${ }^{8}$ muestra tres isotipos que responden al modelo objeto de análisis (acompañados de presentaciones en texto que los singularizan: Última hora en directo, Cronología diaria y Enlaces multimedia), referidos respectivamente a la actualidad del tema, a un calendario de la crisis y, finalmente, a un enlace de vídeos. En los tres domina un fondo celeste atenuado sobre los que se superponen relieves blancos y tonos rojizos. El "isotipo" fundamental, que se repite en el interior de la hoja de calendario fuertemente reducido, muestra un círculo rosáceo tachonado en cruz levemente inclinada con dos clavos más pequeños, como chinchetas, como un símbolo lejanamente medievalizante (de cruz templaria). El motivo se repite,

${ }^{7}$ Grupo Joly.

${ }^{8}$ Grupo Vocento. 
García-Manso, A.

Iconografias en prensa digital sobre la pandemia de COVID-19: un retrato cultural del coronavirus en España en abril de 2020

inclinado en dirección opuesta, como habiendo rotado levemente, en el icono referido a la cronología y en el interior de una hoja de calendario. Finalmente, el tercer logotipo muestra una estilizada rueda dentada en blanco en cuyo interior destaca en rojo el triángulo direccional de "avance" o "play", aceptado ya universalmente y alusivo a los contenidos multimedia. La idea de rotación $-\mathrm{y}$, por consiguiente, con el modelo de la rueda dentada como referente- es, además del motivo del soliforme tachonado que gira, la que permite considerar la secuencia como conjunto, a la vez que denota el carácter dinámico de los datos referidos a los contagios y su morbilidad, reforzada esta última por el símbolo de la cruz, sea de la Cruz Roja (emblema sanitario de reconocimiento planetario, aunque con motivos centrales que varían según las culturas y religiones) o de su reflejo específicamente cristiano, que también se encuentra, aunque con otros tonos pero sobre fondo azul en la bandera de Asturias?.

\section{CRISIS DEL CORONAVIRUS}
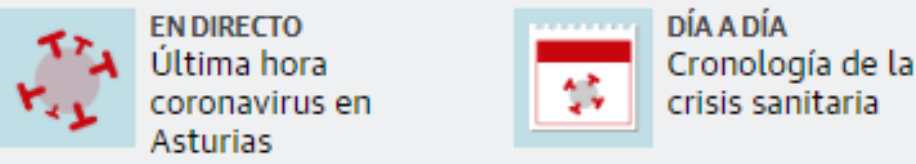

MULTIMEDIA

Vídeos explicativos sobre la epidemia

Ilustración 6: Vínculos de portada digital del diario El Comercio de Asturias.

Fuente: El Comercio de Asturias, abril de 2020.

$\mathrm{Al}$ dinamismo descrito ${ }^{10}$ se suman otras propuestas con un único logotipo, como el de la cabecera también asturiana de La Nueva España ${ }^{11}$ en su versión digital, en la que se propone un montaje donde superponen sobre un fondo gris azulado tres soliformes rosáceos con dos manchas en rojo más intenso, como máculas de infección o de edad, de forma que a la idea de propagación se añade la alusión a personas mayores mediante la mostración de una especie de máculas de pigmentación cutánea.

\footnotetext{
${ }^{9}$ El mapa regional es cambiado por uno nacional en otras cabeceras del mismo grupo Vocento, caso del diario Hoy, que se edita en Badajoz y Cáceres; la relevancia visual viene dada por una imagen en formato GIF (de animación comprimida) mediante la que se expande levemente el icono del soliforme dentado. También el diario El País (grupo PRISA) presenta unos motivos geográfico e icónico concomitantes.

10 En los vínculos que la versión digital de El Heraldo de Aragón (grupo Heraldo de Aragón) dedica a la crisis del coronavirus/Covid-19 predominan los tonos azules, sin estridencias a este respecto.

11 Prensa Ibérica S.A.
} 
García-Manso, A.

Iconografias en prensa digital sobre la pandemia de COVID-19: un retrato cultural del

coronavirus en España en abril de 2020

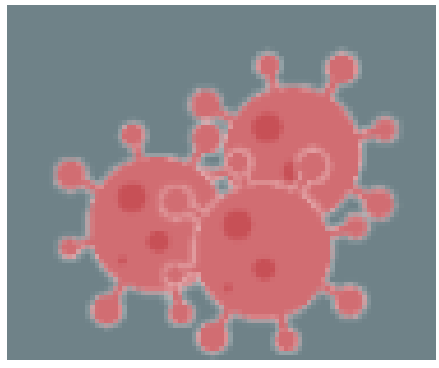

Ilustración 7: Vínculo de portada digital del diario La Nueva España.

Fuente: La Nueva España, abril de 2020.

Con un sentido de fondo más connotado ideológicamente, $L a$ Razón ${ }^{12}$ recurre a una gráfica ascendente en la que, sobre un fondo rojo brillante, parecen escalar cuatro ruedas dentadas de otras tantas moléculas de coronavirus. La propuesta, al margen del alarmismo implícito que desprende, multiplica el icono del agente infeccioso sobre una tabla estadística, sinónimo del carácter pandémico de la enfermedad y de sus consecuencias.

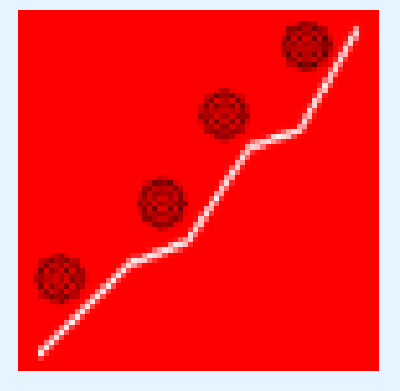

Ilustración 8: Vínculo de portada digital del diario La Razón.

Fuente: La Razón, abril de 2020.

Según se ha analizado ya, la idea de diseminación que impone la pandemia se deposita gráficamente en los rayos del icono soliforme, los cuales, por lo demás, reproducen el fenómeno contrario, la penetración en la célula a través de unos extremos de ventosa. Es más, la difusión en onda nace de las estructuras de corona circular que predomina en las propuestas de "isotipos" consideradas en líneas precedentes. A este respecto, el equipo infográfico del diario El Mundo ${ }^{13}$ recurre a una elaborada secuencia de iconos que retoman los dos aspectos recién señalados: rayos lineales y ondas singulares. Se trata de cinco iconos de soliforme, tres de color negro sobre fondo rojo, y dos de negativos rojos sobre fondo negro (cuando hay tres contrastes o más en juego: rojo-negro-rojo o, como en último logo, rojo-negro-rojonegro).

\footnotetext{
12 Grupo Planeta.

13 Unidad Editorial S.A.
} 
La propuesta resalta el dramatismo de la situación, pero, sobre todo, es indicio de reutilización y revisión de iconos, procesos que consigue de forma lograda. Así, la corona circular del "isotipo" cuyo corazón es la rueda dentada se convierte en ondas en expansión concéntrica, la rueda dentada pasa a ocupar el centro geográfico del país ${ }^{14}$ o el lugar del cerebro en una cabeza humana, la misma rueda dentada se transforma fuente de ondas en paralelo del icono característico de la tecnología inalámbrica Wi-Fi (el cual se inspira en el formato del faro marítimo y del rádar) y, finalmente, aparece dentro de un sobre de correos abierto.

La identificación de cada "isotipo" con su función resulta precisa en los tres primeros casos (noticias, síntomas y mapa), no tanto en lo que se refiere a "podcasts" y "newsletters" en los dos últimos iconos, mediante la irónica referencia que se hace a la Wi-Fi y con la imagen de un sobre de correos (aunque las noticias de última hora no únicamente se reciben en el correo electrónico, sino en otras plataformas) como marco de la rueda dentada que representa el virus. De cualquier forma, al margen de la secuencia, cada icono por separado resulta eficaz, pues enriquece el motivo central en diálogo con otros entornos icónicos (en forma de ondas, mapas, siluetas, Wi-Fi o sobres, según se ha descrito).
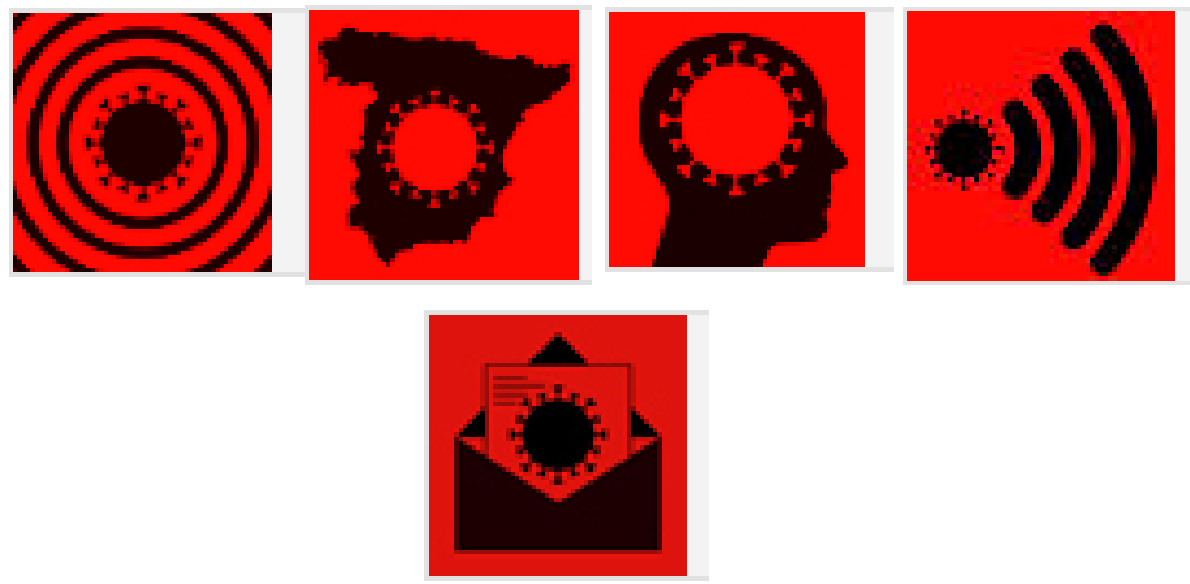

Ilustración 9: Vínculos de portada digital del diario El Mundo.

Fuente: El Mundo, abril de 2020.

\section{RESULTADOS: LOS “ISOTIPOS" DE CORONAVIRUS/COVID-19 Y LA ICONOGRAFÍA GRECOLATINA: LA GORGONA MEDUSA}

El tándem "soliforme/corona radial" (o rueda dentada) constituye el "isotipo" básico de coronavirus/COVID-19 que se está generalizando como icono de enlace para "apps", para "vínculos" informáticos de prensa digital relacionados con la pandemia, y, en general, como su referente visual. Ahora bien, el motivo no está aislado en la historia cultural de Occidente, en la que la suma "soliforme/rueda

14 En el mes de mayo de 2020, de acuerdo con los inicios de los procesos del denominado “desescalamiento", este icono es cambiado por un diseño geométrico en espiga horizontal. 
dentada" se puede identificar también con una cabellera astronómica, aunque no exclusivamente en forma de corona (sobre el simbolismo iconográfico y sus connotaciones desde perspectivas culturales y artísticas, véase el estudio clásico de Gombrich, 2003). La imagen de la cabellera solar resulta, no obstante, positiva para el contexto catastrófico que subyace en la pandemia del año 2020. La misma tradición iconográfica occidental, de raíces grecolatinas, aporta un imaginario fatal encarnado en la mitología monstruosa de las Gorgonas, entre las que la figura de Medusa resulta la más conocida. Y es que esta, a pesar de ser la única mortal de entre las tres Gorgonas, ocupa el lugar más relevante a partir de las peripecias del héroe Perseo, que logró vencerla al decapitarla. Es decir, Medusa es, ante todo, una cabeza, una cabellera que envuelve un rostro. Sus cabellos están formados por serpientes y sus ojos (aun muerta) tienen la facultad de petrificar a quien los contempla y se ve reflejado en ellos; es decir, se trata de una mirada que mata. A este respecto, lo destacable iconográficamente es la identificación de Medusa con una cabellera enmarañada, cuya capacidad terrorífica justifica su aparición en los escudos de los guerreros, como forma de amedrentar al enemigo que tienen enfrente (Vernant, 1996).

La iconografía de Medusa (y, en general, de las Gorgonas) aparece en piezas cerámicas, bajorrelieves y, sobre todo, mosaicos del mundo grecorromano. Llama la atención que, además del relato referido a Perseo, o a otros mitos menos conocidos, lo habitual es la aparición como cabeza, tal como perfectamente se puede contemplar, por poner tres ejemplos, en los mosaicos conservados en el Museo delle Terme ("Cabeza de Medusa”, Roma, s. I-II d.C.), el Sousse Museum ("Cabeza de Medusa”, Túnez, s. II d.C.), o el National Archaeological Museum ("Medusa del Pireo", Atenas, s. II d.C.). La iconografía de la cabeza de Medusa se basa en un rostro rodeado radialmente con una cabellera de serpientes; en ocasiones, sobre todo en manifestaciones más arcaicas, dicho rostro aparece con un gesto grotesco.
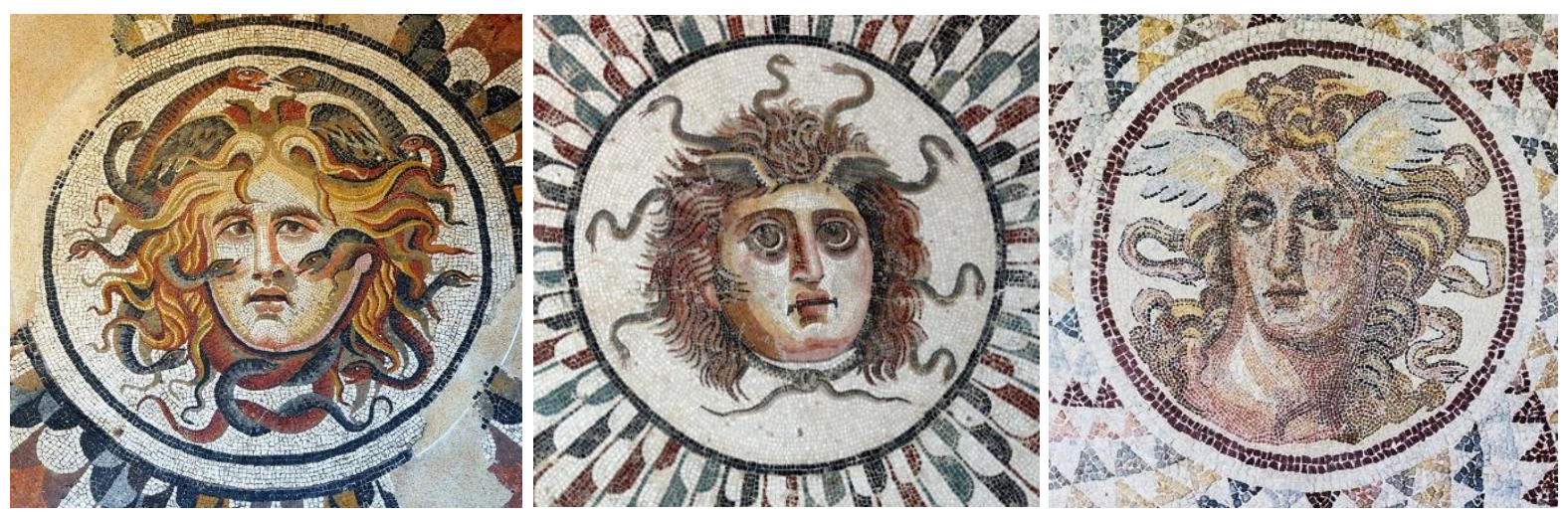

Fotos 1-3: Mosaico "Cabeza de Medusa" (fragmento), Mosaico "Cabeza de Medusa" (fragmento), Mosaico “Medusa del Pireo" (fragmento).

Fuente: Museo delle Terme (Roma), Sousse Museum (Túnez), National Archaeological Museum (Atenas). 
El hecho de que se trate también de un tema que aparece en escudos de combate revela su carácter apotropaico, es decir, de conjura y defensa, sea del soldado o de la casa en lo que concierne a los mosaicos; y es que, en efecto, llegó a existir un amuleto específico denominado "gorgoneion" que se llevaba desde muy antiguo como protección personal (Vázquez y del Hoyo, 1990). Por otra parte, ya en el Renacimiento, el surgimiento del género de los emblemas, tan próximo en cierta forma al diseño iconográfico, el texto no describe la imagen, sino que la comenta, de forma que lo relativo a la Gorgona Medusa resalta su doble cariz, según se descubre, entre otros, en Andrea Alciato y Cesare Ripa, referidos respectivamente a la mortalidad de la tumba (emblema 156 de Alciato) y al espanto (emblema dedicado al "Spavento" en Ripa), con serpientes en uno y otro caso (acerca de las transformaciones iconológicas en el Renacimiento, véase Seznec, 1983). En efecto, los ofidios aportan en la Antigüedad y el Renacimiento una doble lectura, como portadoras de ponzoña y venenos y de antídotos o vacunas; no en vano aparecen como elemento icónico de la vara de Asclepios/Esculapio, patrón de la medicina (Anía, Asenjo y Suárez, 2002).

Por lo demás, la misma disposición de los cabellos-serpientes invita a desarrollar los mosaicos con ampliaciones geométricas, como ondas, además de que, a la manera del escudo redondo, las cabezas aparezcan enmarcadas en uno o varios círculos concéntricos, mediante los que, de alguna manera, amplifica su influencia protectora al conjunto de la edificación y no sólo a la estancia donde se encuentra el mosaico. Finalmente, el hecho de que se trate de una cabeza reforzó su lectura como máscara, es decir, como ilustración de un carácter agresivo al margen de su función como guardián.

En suma, la disposición radial y la geometría en corona, la función amenazante y defensora al tiempo y la tendencia al esquematismo como emblema de escudo de guerra contribuyen a establecer paralelismos con los iconos digitales considerados en relación con el tratamiento gráfico que en la prensa digital de España está mereciendo el coronavirus/COVID-19. Es cierto que no aparece rostro, pero ello se hace en buena medida con el fin de evitar que el enlace o vínculo sea percibido como emoticono, un irónico sistema contemporáneo de claves expresivas para la comunicación digital; no obstante, ello no impide su tratamiento como emblema, definido este como figuración convencional y comentario de la imagen. De hecho, el carácter bífido de la lengua de los ofidios coincide con el aspecto de ventosa de los extremos radiales del coronavirus responsable de la COVID-19. Tales concomitancias son de carácter cultural y giran en torno a un ente monstruoso en uno y otro caso, además de ligado a la atrocidad de la enfermedad y la muerte potencial.

\section{DISCUSIÓN: LAS DOS CARAS DEL MONSTRUO EN UN MISMO ICONO}

La pandemia implica un contagio generalizado, es decir, un factor asociado a la idea de grupo en contacto y, por consiguiente, de un intercambio que es, de forma redundante, interpersonal y mutuo. Pero también implica el relato de su difusión, o, en otras palabras, una comunicación en forma de intercambio de información que va

Vivat Academia. Revista de Comunicación. 2021, nº 154, 45-61 
más allá de la que puede establecer un individuo concreto. No obstante, en tanto la primera noción se expresa como daño, la segunda constituye una forma de protección; también se presentan como distintas formas de pensar lo concreto (la enfermedad transmitida físicamente) y lo abstracto (lo que se expresa en torno a la afección).

En el análisis que se ha llevado a cabo en los epígrafes precedentes en torno al tratamiento gráfico de los vínculos referidos a coronavirus/COVID-19 en la prensa digital española se constata el funcionamiento de abstracción esquemática que se convierte en forma de referencia a la pandemia en dos frentes: la amenaza y la defensa o escudo. Efectivamente, a partir de la recreación figurativa de la corona dentada que da nombre al tipo de virus causante de la COVID-19, se perfilan diferentes rasgos gráficos que permiten la identificación inmediata de cada vínculo o enlace, así como sus dos sentidos específicos: la incrustación (del virus) y la propagación (de la enfermedad).

De forma llamativa, el mundo occidental ha impuesto no sólo la denominación (a través de lenguas indoeuropeas: el latín a través del inglés) sino la figuración a partir de la iconografía de la Gorgona Medusa en coincidencia con los rasgos citados. Así, la pandemia que ha abatido el planeta desde finales del año 2019, con especial virulencia en el año 2020, ha permitido el establecimiento de unos iconos globales, reconocidos por la práctica totalidad de los seres humanos. Dichos iconos son de carácter predominantemente "isotópicos" (es decir, ilustraciones en las que no hay necesidad expresa de grafismo alfabético), si bien predomina la exposición textual complementaria cuando las ilustraciones apoyan enlaces y vínculos digitales en redes sociales e internet. Finalmente, existen aspectos asociados a la comunicación y la difusión, como es la estadística (la necesidad del control de las cifras) y como es la separación entre enfermedad y contagio (dada la importancia que han adquirido los portadores asintomáticos del virus), que amplían el espectro icónico del "isotipo", tal como se ha visto en relación con la edición digital del diario El Mundo.

Más allá de lo gráfico, el carácter de escudo que presentan los diseños también constituye una reflexión en torno a las relaciones humanas frente a la amenaza de algo invisible. Ello no impide otras lecturas, como la referida a la relación con una naturaleza que parece rebelarse contra el cambio climático y la intervención humana, o una clave expresamente política: los orígenes de la pandemia en China también justificarían el predominio del color rojo en los logotipos, a la vez que abre un campo de reflexión más amplio, con contenidos marcadamente éticos.

El "isotipo" analizado aporta, por consiguiente y en paralelo con la iconografía de la gorgona Medusa, un doble sentido: de un lado, de constatación o retrato de la amenaza y, de otro, de imagen acerca de expansión del conocimiento (herramienta que frena la extensión de la enfermedad). Y es que, a falta de una vacuna que amortigüe los catastróficos efectos del virus, la difusión de los datos se ha convertido en el antídoto más eficaz, y ello acaso por primera vez en la historia de la cultura 
García-Manso, A.

Iconografias en prensa digital sobre la pandemia de COVID-19: un retrato cultural del coronavirus en España en abril de 2020

humana y con todas las prevenciones relativas a la posibilidad de que, a la vez que información eficaz, se expandan datos manipulados y tendenciosos.

En suma, de alguna manera, reflexionar acerca de las características de la comunicación sobre una molécula cuyo rasgo más evidente es la propia invisibilidad y cuyo proceso biológico es de réplica y, por lo tanto, de comunicación, contribuye a trascender la enfermedad y el contagio, a conferirles un sentido a la vez coyuntural y universal: otra forma de comprender la contemporaneidad del fenómeno y combatir el virus desde unos mecanismos a la vez antiguos y nuevos.

\section{REFERENCIAS}

Anía Lafuente, B. J., Asenjo González, M. \& Suárez Almenara, J. L. (2002). Los verdaderos símbolos de la medicina: la serpiente y el bastón de Asclepio, pero no el caduceo, en Medicina Clínica, 119, 336-338.

Baldwin, C. L. \& Runkle, R. S. (1997). Biohazards symbol: Development of a biological Hazards warning Signal, en Science, 158, 264-265.

Barthes, R. (1991; edic. original de 1970). El imperio de los signos. Barcelona: Mondadori.

Cairo, A. (2008). Infografía 2.0, visualización interactiva de información en prensa. Madrid: Alamut.

Carazo Lefort, E. \& Galván Desvaux, N. (2017). Diagramas: Del Isotype al GIF. Notas para una didáctica del análisis gráfico en arquitectura, en EGA Expresión Gráfica Arquitectónica, 30, 30-42. https://doi.org/10.4995/ega.2017.7215

Costa, J. (1998). La esquemática. Visualizar la información. Barcelona: Paidós.

De Pablos, J. M. (1999). Infoperiodismo: el periodista como creador de infografía. Madrid: Síntesis.

Gamonal, R. (2013). Infografía: etapas históricas y desarrollo de la gráfica informativa, en Historia y Comunicación Social, 18, 335-347.

Gombrich, E. H. (2003). Los usos de las imágenes. Estudios sobre la función social del arte y la comunicación visual. Barcelona: Debate.

Orero García, P. y Cebrián Enrique, B. J. (2019). Evolución del hipertexto en la prensa escrita (2002-2016), en El profesional de la información, 28. https://doi.org/10.3145/epi.2019.mar.25 
García-Manso, A.

Iconografias en prensa digital sobre la pandemia de COVID-19: un retrato cultural del coronavirus en España en abril de 2020

Otero López, M., López García, X. \& González Veira, X. (2012). Diseño y visualización de la información. Caracterización del mensaje infográfico en los diarios españoles, en ZER, 33, 143-165.

Panofsky, E. (2008; edic. original de 1955). El significado en las artes visuales. Madrid: Alianza.

Peirce, C. S. (1998). El hombre, un signo. Barcelona: Crítica.

Peltzer, G. (1991). Periodismo iconográfico. Madrid: Rialp.

Seznec, J. (1983). Los dioses de la Antigüedad en la Edad Media y en el Renacimiento. Madrid: Taurus.

Vázquez Hoys, A. M. y Del Hoyo Calleja, J. (1990). La Gorgona y su triple poder mágico (aproximación a la magia, la brujería y la superstición II), en Espacio, Tiempo Forma. Historia Antigua, 3, 117-182.

Vernant, J. P. (1996). La muerte en los ojos. Figuras del otro en la antigua Grecia. Barcelona: Gedisa.

\section{AUTORA}

\section{Angélica García-Manso}

Investigadora y profesora universitaria y de Secundaria y Bachillerato; es Doctora en Historia del Arte por la Universidad de Extremadura en el programa "El arte como diálogo y transmisión interculturales y transfronterizos" con una tesis sobre la interrelación entre las artes (fundamentalmente, literatura e imagen, sea iconográfica, mitológica o propiamente figurativa en la pintura y el Séptimo Arte). Entre sus estudios más representativos sobre la interrelación entre las artes se cuentan: " Nibelungos* ("Die Nibelungen*, 1924), de Fritz Lang: un imaginario mitológico de raíces pictóricas", en S. Bouso et alii. La pantalla ficticia: literatura y tecnologías de la Comunicación (Madrid, 2016); o "*Los Pájaros*: la distopía que Daphne du Maurier legó a la literatura y las demás artes", en E. Encabo et alii, Sagas, distopias y transmedia: ensayos sobre ficción fantástica (León, 2016). Pertenece al Grupo de Investigación MUSAEXI, de la Universidad de Extremadura.

angelica.manso@hotmail.com

Orcid ID: http:// orcid.org/0000-0002-9068-9379

Google Scholar: https://scholar.google.es/citations?user=dUeliaEAAAAJ\&hl=es

ResearchGate: https://www.researchgate.net/profile/Angelica_Garcia-Manso

Scopus: https:// www.scopus.com/authid/detail.uri?authorId=57195586594

Academia.edu: https://unex.academia.edu/Ang\%C3\%A9licaGarc\%C3\%ADaManso 